\title{
Seafloor Video Footage and Still-Frame Grabs from U.S. Geological Survey Cruises in Hawaiian Nearshore
} Waters

Data Series 735
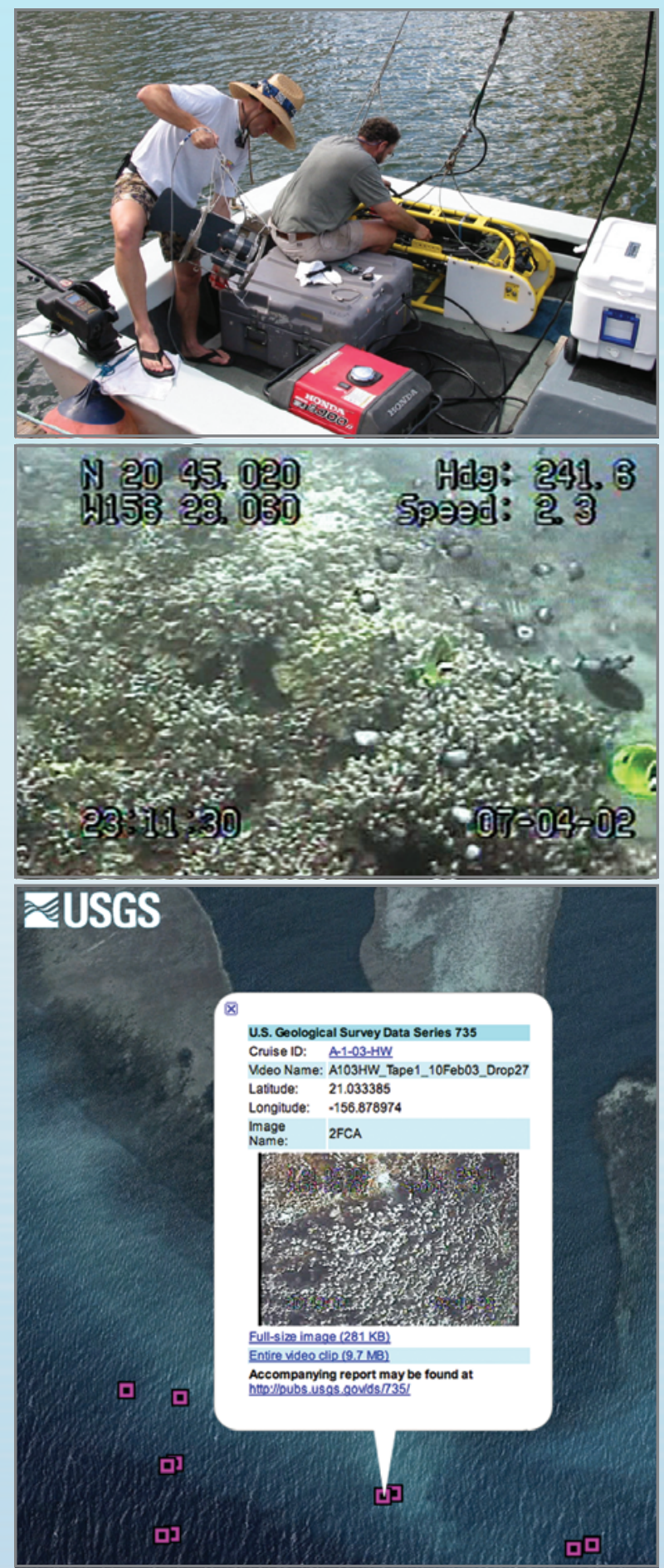

U.S. Department of the Interior

U.S. Geological Survey 
FRONT COVER

Upper: Eric Grossman (I) and Hank Chezar (r), both of the USGS, preparing the underwater camera systems for deployment in Hawaiian waters. Center: Example of a still image captured from underwater video footage. Lower: Screenshot of information popup balloon included in Google Earth kml files that are available for download with the data series. 


\section{Seafloor Video Footage and Still-Frame Grabs from U.S. Geological Survey Cruises in Hawaiian Nearshore Waters}

By Ann E. Gibbs, Susan A. Cochran, and Peter W. Tierney

Data Series 735 


\section{U.S. Department of the Interior \\ KEN SALAZAR, Secretary \\ U.S. Geological Survey \\ Marcia K. McNutt, Director}

U.S. Geological Survey, Reston, Virginia: 2013

For product and ordering information: World Wide Web: http://www.usgs.gov/pubprod Telephone: 1-888-ASK-USGS

For more information on the USGS - the Federal source for science about the Earth, its natural and living resources, natural hazards, and the environment: World Wide Web: http://www.usgs.gov

Telephone: 1-888-ASK-USGS

Any use of trade, firm, or product names is for descriptive purposes only and does not imply endorsement by the U.S. Government.

Although this report is in the public domain, permission must be secured from the individual copyright owners to reproduce any copyrighted material contained within this report.

Suggested citation:

Gibbs, A.E., Cochran, S.A., and Tierney, P.W., 2013, Seafloor video footage and still-frame grabs from U.S. Geological Survey cruises in Hawaiian nearshore waters: U.S. Geological Survey Data Series 735, 11 p. 


\section{Contents}

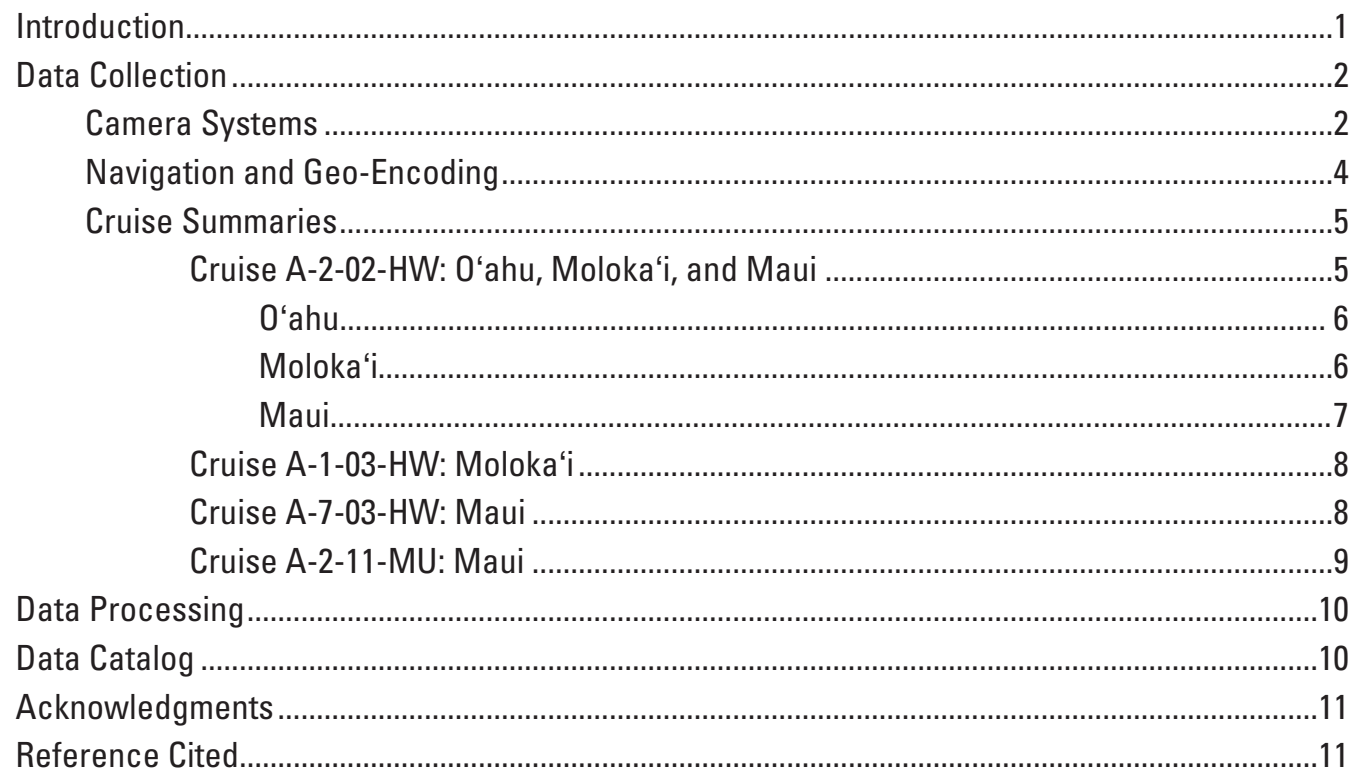

\section{Figures}

1. Index map of eight main Hawaiian Islands, showing location of study area.............................1

2. Study area in the main Hawaiian Islands, with locations of towed-camera transects and drop-camera stations during cruises from 2002 to 2011 ...........................................

3. Photographs of camera systems used to collect underwater videos..............................................

4. Photograph of the research vessel Alyce $C$ leaving Ma'alaea Harbor, Maui..............................3

5. Photograph of shipboard laboratory setup for navigation, recording of ship's position, and feature annotation ..................................................................................................

6. Typical layback for the SEAVIEWER towed-camera system as a function of ship speed and camera depth ................................................................

7. South shore of the island of $\mathrm{O}^{\prime}$ ahu, showing locations of towed-camera transects from survey cruise A-2-02-HW ......................................................................

8. South shore of the island of Moloka'i, showing locations of towed-camera transects and drop-camera stations from cruise A-2-02-HW ........................................

9. Northwest shore of the island of Maui, showing locations of towed-camera transects from cruise A-2-02-HW ..............................................................................

10. South shore of the island of Moloka'i, showing locations of drop-camera stations from survey cruise A-1-03-HW ............................................................................................ 8

11. West coast of the island of Maui, showing locations of drop-camera stations from cruise A-7-03-HW..............................................................................

12. West coast of the island of Maui, showing locations of towed-camera transects and drop-camera stations from cruise A-2-11-HW 
13. Typical still image as it is first captured from the video footage and after elimination of interlacing effects.

14. Screenshot showing popup informational balloon included in Google Earth kml files..........11

\section{Tables}

1. Camera system, navigation equipment, and original media for each island survey ..................4

2. Data collected during each cruise .....................................................................................

3. Descriptions of main attributes included in shapefiles ..............................................................11 


\title{
Seafloor Video Footage and Still-Frame Grabs from U.S Geological Survey Cruises in Hawaiian Nearshore Waters
}

\author{
By Ann E. Gibbs, Susan A. Cochran, and Peter W. Tierney
}

\section{Introduction}

Underwater video footage was collected in nearshore waters ( $<60$-meter depth) off the Hawaiian Islands from 2002 to 2011 as part of the U.S. Geological Survey (USGS) Coastal and Marine Geology Program's Pacific Coral Reef Project (fig. 1), to improve seafloor characterization and for the development and ground-truthing of benthic-habitat maps. This report includes nearly 53 hours of digital underwater video footage collected during four USGS cruises and more than 10,200 still images extracted from the videos, including still frames from every 10 seconds (s) along transect lines, and still frames showing both an overview and a near-bottom view from fixed stations. Environmental Systems Research Institute (ESRI) shapefiles of individual video and still-image locations, and Google Earth kml files with explanatory text and links to the video and still images, are included.

This report documents the various camera systems and methods used to collect the videos, and the techniques and software used to convert the analog video tapes into digital data in order to process the images for optimum viewing and to extract the still images, along with a brief summary of each survey cruise. Navigation and other information is posted online at:

http://walrus.wr.usgs.gov/infobank/a/a202hw/html/a-2-02-hw.meta.html

http://walrus.wr.usgs.gov/infobank/a/a103hw/html/a-1-03-hw.meta.html

http://walrus.wr.usgs.gov/infobank/a/a703hw/html/a-7-03-hw.meta.html

http://walrus.wr.usgs.gov/infobank/a/a0211mu/html/a-02-11-mu.meta.html

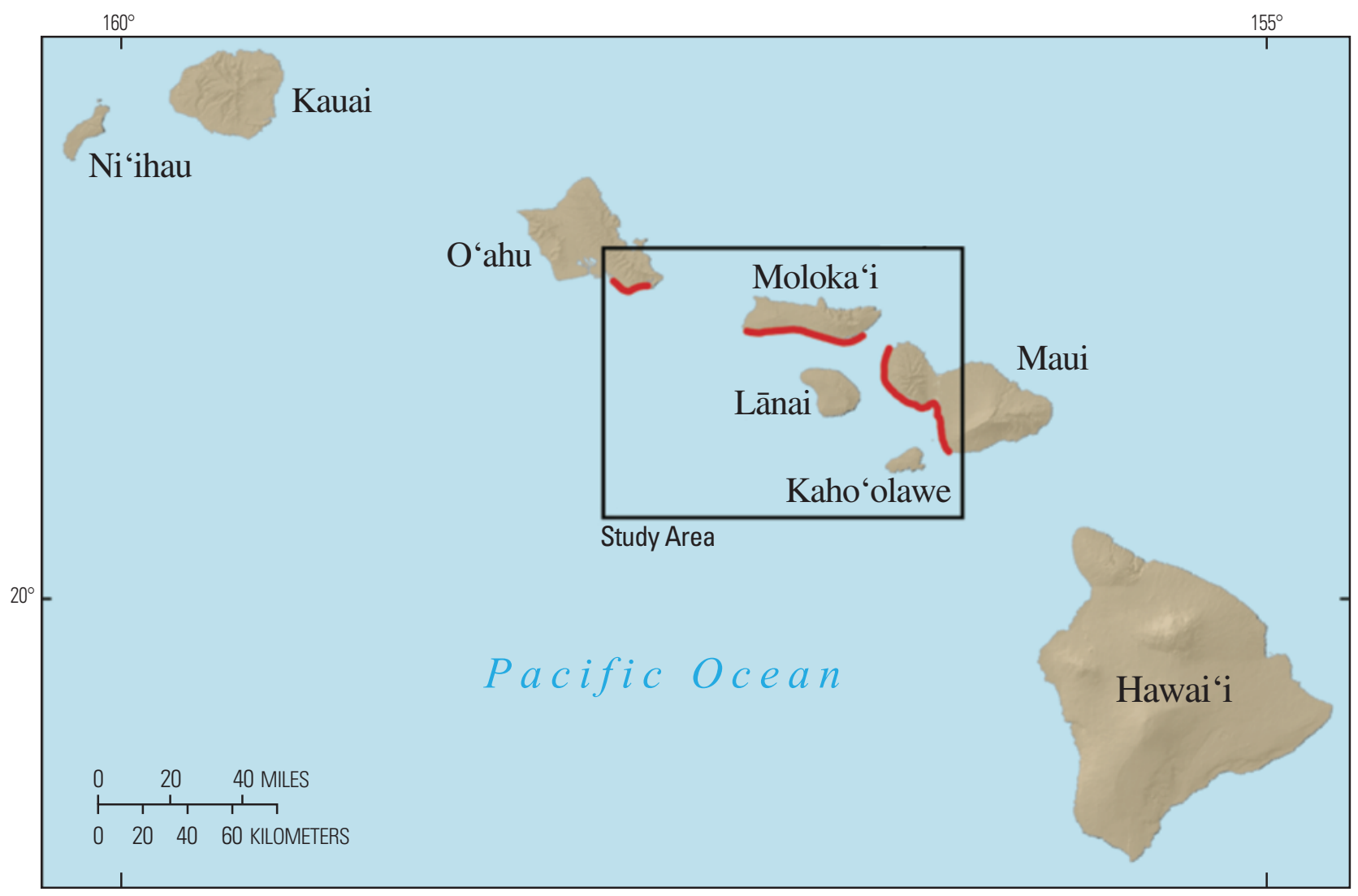

Figure 1. Index map of eight main Hawaiian Islands, showing location of study area (see fig. 2). Red lines indicate areas where underwater video footage was collected. 


\section{Data Collection}

Nearly 53 hours of underwater video footage along 101 towed-camera transect lines and from 770 drop-camera stations was collected during four cruises from 2002 to 2011 (fig. 2). The videos were collected with one of four camera systems (SLED, SEAVIEWER, SONY, or SPLASHCAM, fig. 3) that were either towed behind the vessel while underway or by dropping the camera over the side while the vessel occupied a fixed station or was drifting slowly.

Towed-camera videos were typically collected from the shallowest depth accessible onshore to offshore, ending where (1) either the benthic environment was coral free or the seafloor was an unchanging vegetated or nonvegetated sand sheet, (2) the limit of visibility was reached, or (3) maximum cable $(\sim 60 \mathrm{~m})$ had been deployed. Transects typically started in water depths of about $10 \mathrm{~m}$ and extended to as much as $40 \mathrm{~m}$ depth. At some locations, shore-parallel transects were collected to obtain more detailed information on alongshore variations and to better define transitions in bottom type and (or) coral reef environments.

Drop-camera videos were collected at individual stations in water depths ranging from 4 to $60 \mathrm{~m}$. The camera was deployed and retrieved manually, sometimes assisted by an electric winch. Video footage was collected at similar water depths along multiple shore-normal transects and at additional sites of interest.

The vessel used during all surveys was the 9.8-m Alyce $C$, owned and operated by Captain Joe Reich of Moloka'i (fig. 4).

\section{Camera Systems}

The SLED camera system, fabricated by the USGS in 2002, includes two video cameras - one looking down vertically at nadir, and the other looking slightly ahead at an oblique angle along track (fig. $3 A$ ). The camera system also included high-intensity-discharge (HID) xenon lights, two lasers, a depth transducer, and a conductivity/temperature (CT) sensor, all mounted in a robust sled frame. Because of the size and weight of the SLED system, it was deployed from a hydraulic winch and towed behind the vessel.

The SEAVIEWER camera system, also fabricated by the USGS in 2002, consists of a watertight SeaViewer video camera with a light-emitting diode (LED) light ring (http:// www.seaviewer.com, last accessed August 15, 2012) that can be configured for towing or on-station drops. When rigged for towing, the camera and light were mounted in a small aluminum hand-held frame with a rear-mounted plastic fin; the frame could be manually deployed behind the vessel (fig. $3 B$ ). When rigged for on-station dropping, the camera and light

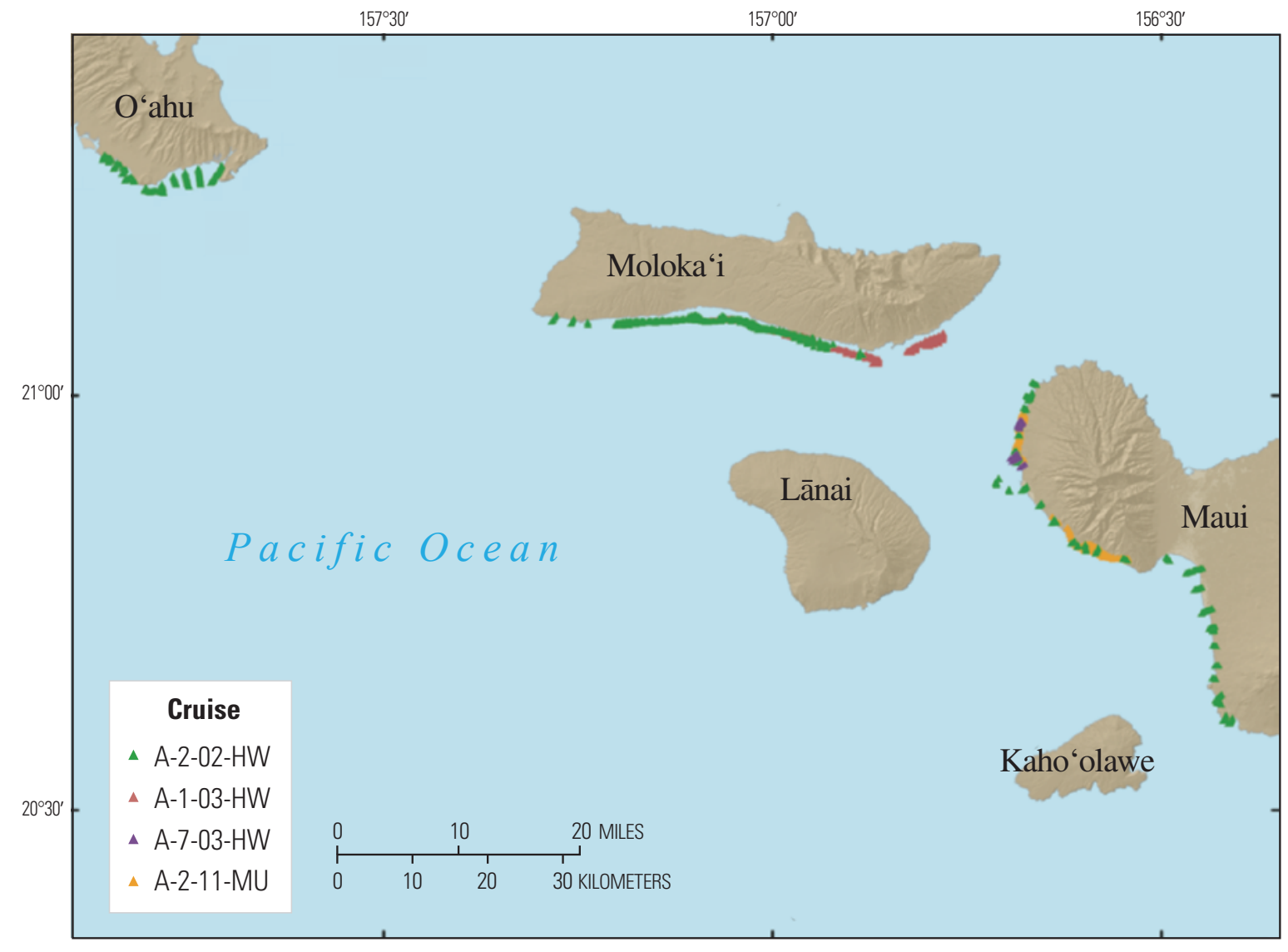

Figure 2. Study area in the main Hawaiian Islands, with locations of towed-camera transects and dropcamera stations during cruises from 2002 to 2011. 

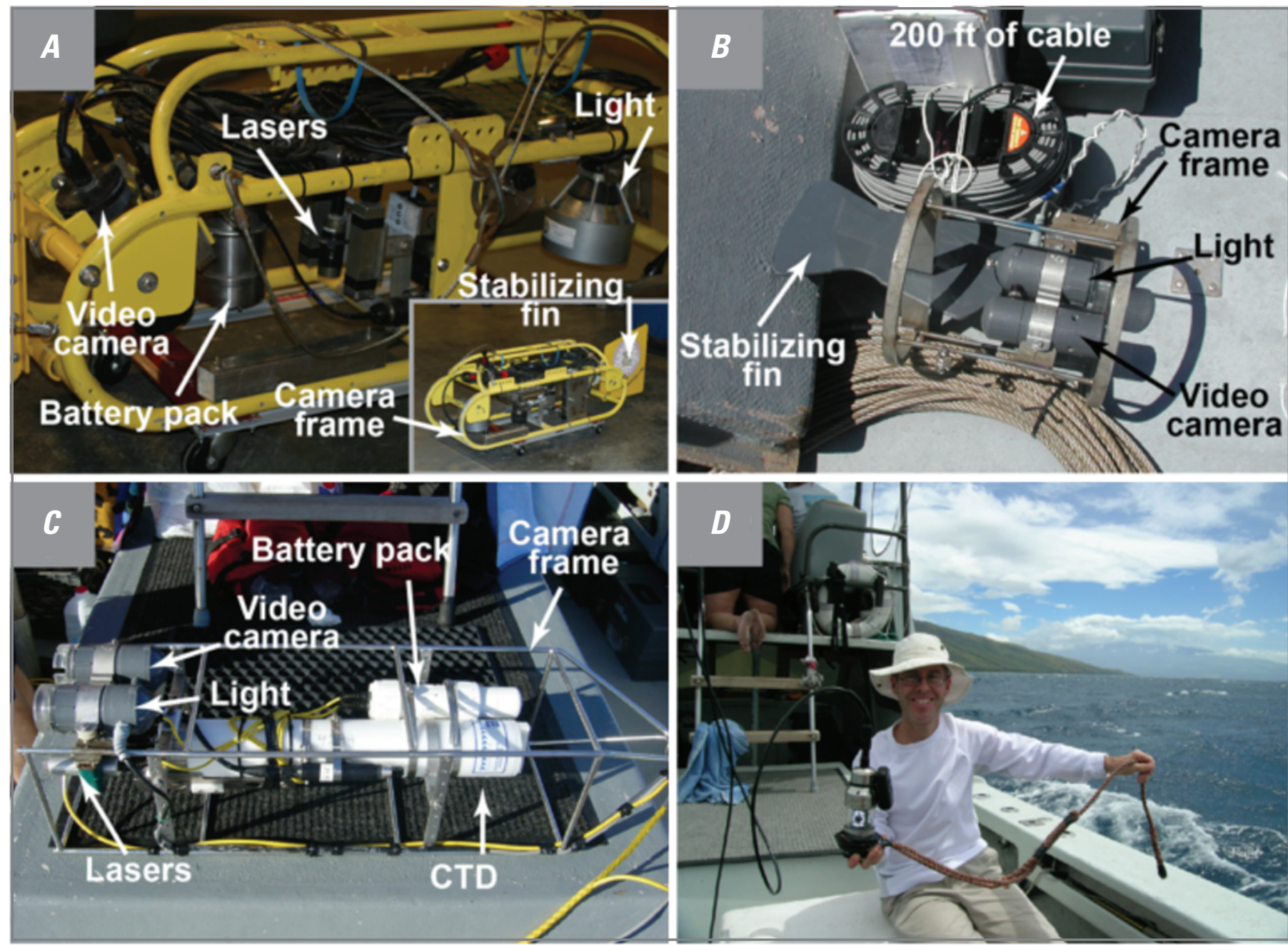

Figure 3. Photographs of camera systems used to collect underwater videos. $A$, SLED. $B$, SEAVIEWER shown rigged for towing. $C$, SEAVIEWER, along with a CTD sensor, shown rigged for drops. D, SPLASHCAM with U.S. Geological Survey ocean engineer Gerry Hatcher.

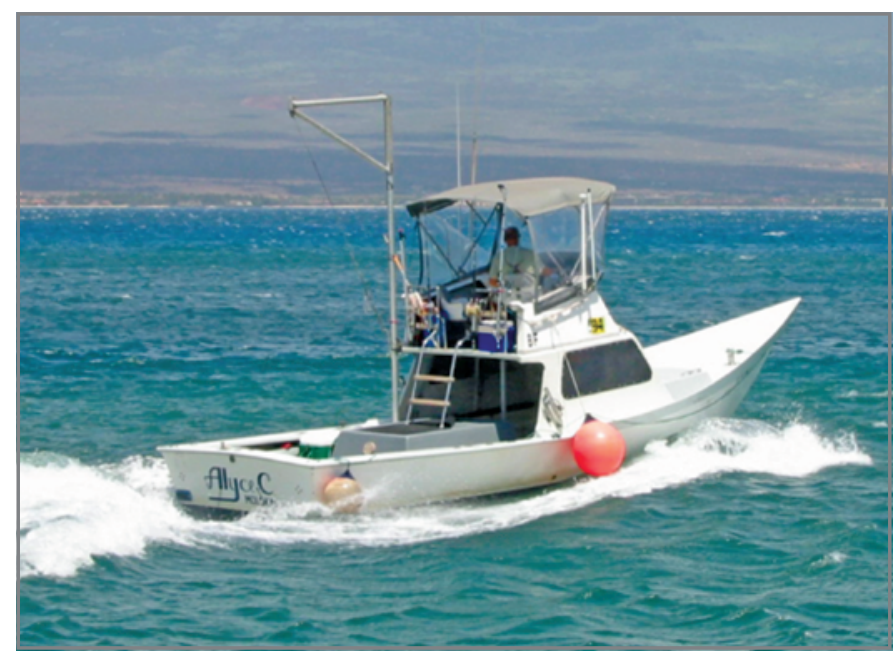

Figure 4. Photograph of the research vessel $A / y c e C$ leaving Ma'alaea Harbor, Maui. were integrated with two battery-powered lasers and, at times, additional instruments, such as a conductivity/temperature/ depth (CTD) sensor (fig. 3C).

The SPLASHCAM consists of a Sidewinder 360 video camera made by Splashcam (http://www.splashcam.com, last accessed August 15, 2012) equipped with depth, temperature, and direction sensors. The video signal came from either a downward- or side-looking Sony 8.5-millimeter $(\mathrm{mm})$ charge-coupled-device (CCD) camera mounted in a watertight submersible housing (fig. $3 D$ ).

Because of the typically clear Hawaiian waters and bright ambient light at the seafloor, gross seafloor characteristics could usually be interpreted in water as much as $50 \mathrm{~m}$ deep when the camera systems were on the surface. The quality and detail of the imagery increased as the cameras approached the seafloor. For safety and the protection of corals, towed cameras never approached closer than about $5 \mathrm{~m}$ above the seafloor. When dropped vertically over the side of the vessel at 
Table 1. Camera system, navigation equipment, and original media for each island survey.

[USGS, U.S. Geological Survey]

\begin{tabular}{|c|c|c|c|c|c|c|c|c|}
\hline \multirow[b]{2}{*}{ USGS cruise } & \multirow[b]{2}{*}{ Island } & \multicolumn{3}{|c|}{ Camera system } & \multicolumn{2}{|c|}{ Navigation equipment } & \multicolumn{2}{|c|}{ Original media } \\
\hline & & SLED & $\begin{array}{c}\text { SEA- } \\
\text { VIEWER }\end{array}$ & $\begin{array}{l}\text { SPLASH- } \\
\text { CAM }\end{array}$ & $\begin{array}{l}\text { Garmin } \\
\text { GPS76 }\end{array}$ & $\begin{array}{l}\text { Novatel } \\
\text { ProPak- } \\
\text { G2Plus }\end{array}$ & $\begin{array}{c}\text { Digital-8 } \\
\text { tape }\end{array}$ & MiniDV \\
\hline A-2-02-HW & $\mathrm{O}^{\prime} \mathrm{ahu}$ & $\mathrm{X}$ & $\mathrm{X}$ & & $\mathrm{X}$ & & $\mathrm{X}$ & \\
\hline A-2-02-HW & Moloka'i & $\mathrm{X}$ & $\mathrm{X}$ & & $\mathrm{X}$ & & $\mathrm{X}$ & \\
\hline A-2-02-HW & Maui & & $\mathrm{X}$ & & $\mathrm{X}$ & & $\mathrm{X}$ & \\
\hline A-1-03-HW & Moloka'i & & $\mathrm{X}$ & & $\mathrm{X}$ & & $\mathrm{X}$ & \\
\hline A-7-03-HW & Maui & & $\mathrm{X}$ & & $\mathrm{X}$ & & $\mathrm{X}$ & \\
\hline A-2-11-MU & Maui & & & $\mathrm{X}$ & & $\mathrm{X}$ & & $\mathrm{X}$ \\
\hline
\end{tabular}

a fixed station, the cameras were allowed to come within tens of centimeters of the seafloor, providing much greater detailed imagery than when towed.

\section{Navigation and Geo-Encoding}

Live video feed from the SLED, SEAVIEWER, and SPLASHCAM camera systems was viewed aboard the vessel in a shipboard laboratory on a standard cathode-ray-tube (CRT) monitor and recorded directly to either Digital-8 and DVD or MiniDV videotapes, depending on the camera system (fig. 5). The time, date, location, and ship speed were overlaid on the video image, using the SeaViewer Sea-Trak GPS Video Overlay system.

Simultaneous navigation, recording of vessel position, and feature annotation were conducted in real time using Red Hen Systems' VMS200 hardware and MediaMapper software (http://www.redhensystems.com, accessed August 15, 2012) on a laptop running Windows XP. Location data were acquired using wide-area augmentation systems (WAAS)-enabled Global Positioning System (GPS) units (Garmin GPS76 and Novatel ProPak-G2plus). National Marine Electronics Association (NMEA)-formatted GPS data was transmitted at 2-s intervals by the VMS200 and recorded onto the first (right) audio channel of the videotape. A breakdown of the camera system and positioning combination, in addition to the original media format, for each cruise is listed in table 1.

Subsequent processing, or indexing, of the audio-encoded videotapes using MediaMapper software allows the creation of a database index to cross-reference GPS locations and video time codes. This technique allowed for navigation and video to be viewed in real time, and the locations of features of interest and comments (for example, start/end of lines, substrate type) to be added to the database during data collection. After each cruise, this technique allowed rapid access to any location or time point on the original video by selecting positions along the navigation trackline within MediaMapper; in this way,
Figure 5. Photograph of shipboard laboratory setup for navigation, recording of ship's position, and feature annotation.

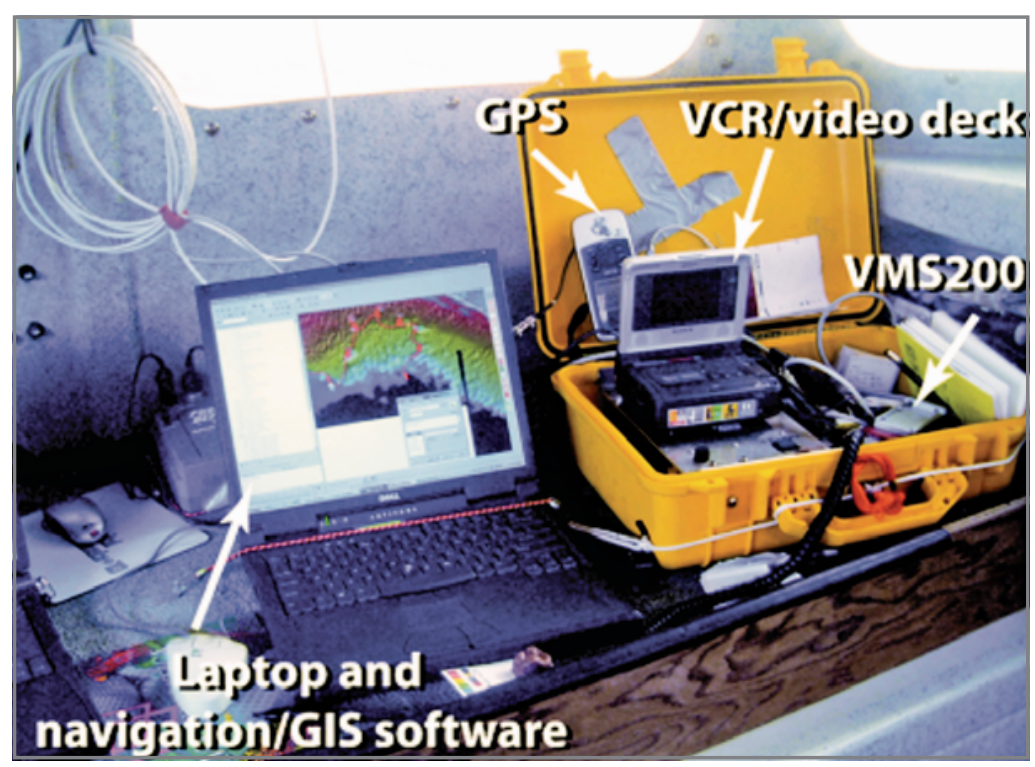


Table 2. Data collected during each cruise.

\begin{tabular}{|c|c|c|c|c|c|c|c|c|c|}
\hline \multirow[b]{2}{*}{ Cruise } & \multirow[b]{2}{*}{ Island } & \multirow[b]{2}{*}{$\begin{array}{c}\text { Start date } \\
\text { (YYYY } \\
\text { MMDD) }\end{array}$} & \multirow[b]{2}{*}{$\begin{array}{c}\text { End date } \\
\text { (YYYY } \\
\text { MMDD) }\end{array}$} & \multicolumn{4}{|c|}{ DATA COLLECTED } & \multicolumn{2}{|c|}{$\begin{array}{c}\text { PROCESSED } \\
\text { DATA }\end{array}$} \\
\hline & & & & $\begin{array}{c}\text { Towed } \\
\text { transects }\end{array}$ & $\begin{array}{l}\text { Length of } \\
\text { towed } \\
\text { transect } \\
(\mathrm{km})\end{array}$ & $\begin{array}{c}\text { Camera } \\
\text { drops }\end{array}$ & $\begin{array}{l}\text { Video } \\
\text { hours }\end{array}$ & $\begin{array}{l}\text { Video } \\
\text { clips }\end{array}$ & $\begin{array}{c}\text { Still } \\
\text { images }\end{array}$ \\
\hline A-2-02-HW & O’ahu & 20020626 & 20020628 & 21 & 22.4 & 0 & 9 & 21 & 1,834 \\
\hline A-2-02-HW & Moloka'i & 20020630 & 20020711 & 23 & 25.5 & 362 & 17 & 385 & 2,842 \\
\hline A-2-02-HW & Maui & 20020703 & 20020706 & 40 & 30.7 & 0 & 11 & 40 & 2,499 \\
\hline A-1-03-HW & Moloka‘i & 20030210 & 20030212 & 0 & $\mathrm{n} / \mathrm{a}$ & 161 & 6 & 161 & 346 \\
\hline A-7-03-HW & Maui & 20030705 & 20030705 & 0 & $\mathrm{n} / \mathrm{a}$ & 32 & 2 & 32 & 70 \\
\hline A-2-11-MU & Maui & 20110319 & 20110321 & 17 & 7.7 & 214 & 8 & 231 & 2,635 \\
\hline TOTAL & & & & 101 & 86.3 & 769 & 53 & 870 & 10,226 \\
\hline
\end{tabular}

the video could be interactively queried, and geographically referenced feature annotations could be added to the database. For compatibility with Google Earth, we provide links to the videos in .MOV format, which retains the audio-encoded information but is incompatible with MediaMapper software. Original and MediaMapper-compatible MPEG2 files are available from the authors.

All navigation information, including the locations of the camera and of any features noted along the video, is

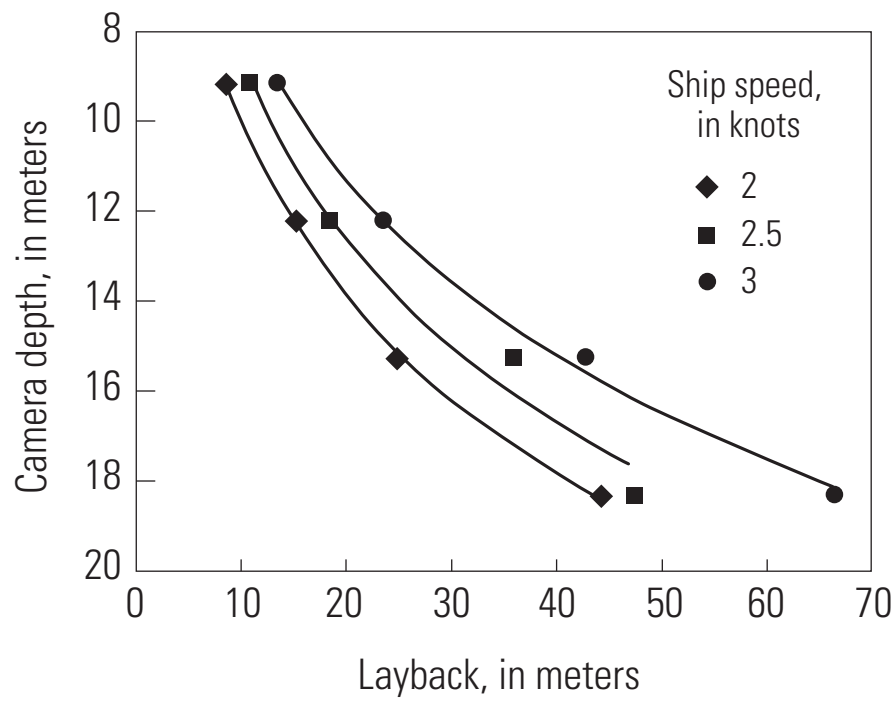

Figure 6. Typical layback for the SEAVIEWER towed-camera system as a function of ship speed and camera depth (modified from Gibbs and others, 2005). referenced to the position of the GPS antenna on board the vessel and not to the physical location of the camera in the water. At drop-camera stations, the offset between the camera location and the recorded GPS location was generally less than $5 \mathrm{~m}$ because the ship was moving slowly $(<1 \mathrm{knot})$ and the camera was in the water only briefly $(<5 \mathrm{~min})$, and so little drag was generated on the camera and cable. At these times, the camera hung nearly straight down over the side. The offset between the GPS and true location of the towed video camera was typically larger. From field observations and an experiment conducted during cruise A-2-02-HW, this offset, or layback, could be as much as $70 \mathrm{~m}$, depending on ship speed, water depth, and length of cable out (fig. 6). Positional data in this report were not corrected for offset nor layback and so represent only approximate locations.

\section{Cruise Summaries}

A brief overview of each of the six cruises, including dates, locations, survey design and objectives, and equipment used, is provided below and summarized in table 2 .

\section{Cruise A-2-02-HW: O‘ahu, Moloka'i, and Maui}

From June 26 to July 11, 2002, underwater video footage was collected off the islands of $\mathrm{O}^{\prime} \mathrm{ahu}$, Maui, and Moloka' $\mathrm{i}$, with both the SLED and SEAVIEWER camera systems and recorded on Digital-8 videotapes. Position information was encoded onto the audio track of the videotapes with the VMS200 system, using GPS information from a Garmin GPS76 WAAS-enabled handheld GPS unit. The data collected from each island is summarized below; for complete details, see the report by Gibbs and others (2005). 


\section{O‘ahu}

From June 26 to 28,2002 , nearly 9 hours, or more than $22 \mathrm{~km}$, of underwater video footage was collected along 21 transects between Kewalo Basin and Koko Head Crater, with both the SLED and SEAVIEWER camera systems (fig. 7; table 2), in water depths ranging from 10 to $40 \mathrm{~m}$. The main objectives of this cruise were to collect groundtruth data for USGS side-scan-sonar, seismic-reflection, and substrate-texture (grain size) surveys and to provide baseline information on coral coverage.

\section{Moloka'i}

From June 30 to July 11, 2002, nearly 17 hours, or more than $25 \mathrm{~km}$, of underwater video footage was collected along 23 towed-camera transects and an additional 362 drop-camera stations, off the south shore of Moloka' $i$, using both the SLED and SEAVIEWER camera systems, (fig. 8), in water depths ranging from 2 to $36 \mathrm{~m}$. The main objectives of this cruise were to characterize the seabed in support of studies on coral community, reef history and development, and reef morphology, and also to collect ground-truth data for benthic-habitat mapping.

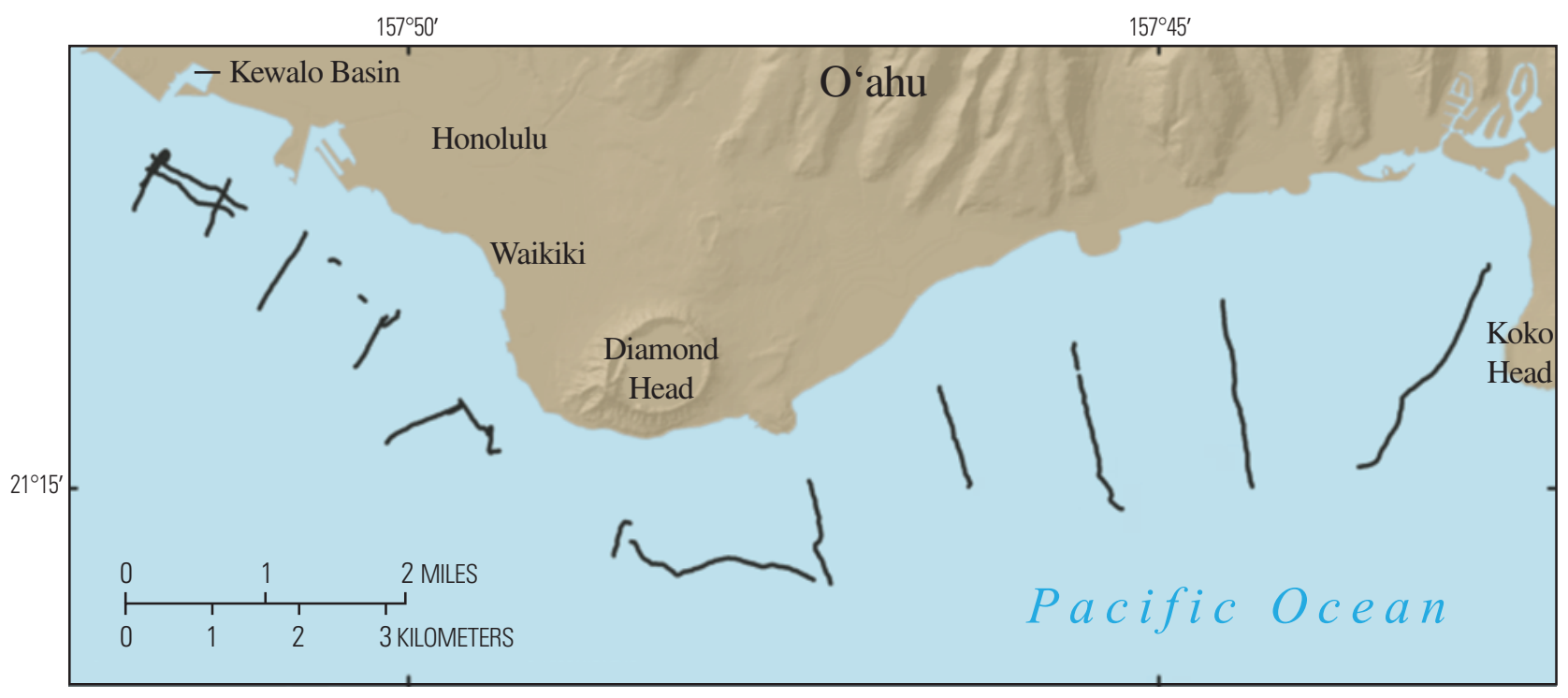

Figure 7. South shore of the island of 0 'ahu, showing locations of towed-camera transects (dark-grey lines) from survey cruise A-2-02-HW.

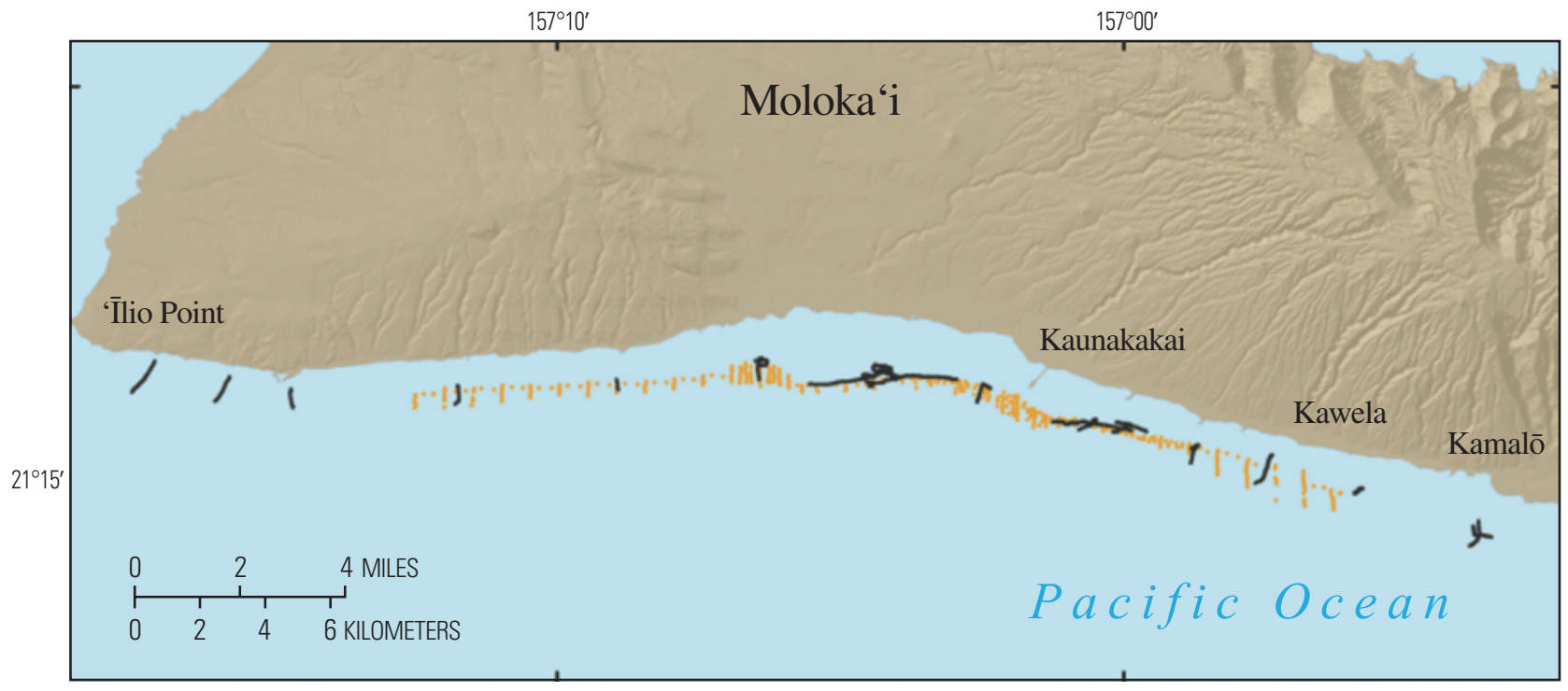

Figure 8. South shore of the island of Moloka 'i, showing locations of towed-camera transects (dark-grey lines) and drop-camera stations (orange lines) from cruise A-2-02-HW. 
Maui

From July 3 to July 6 , 2002, nearly 11 hours, or more than $30 \mathrm{~km}$, of underwater video footage was collected along 40 towed-camera transects between Kahana and 'Ahihi-Kīna'u Natural Area Preserve with the SEAVIEWER camera system (fig. 9), in water depths ranging from 10 to $40 \mathrm{~m}$. In addition, one transect began on the shallow (1-m deep) platform of 'Ahihi-Kīna' $u$, and three transects were collected in water depths of 60 to $70 \mathrm{~m}$ offshore Lahaina. The main objectives of this cruise were to characterize the overall sea-bottom type and to identify regional transitions in reef morphology, coral cover, and coral health.

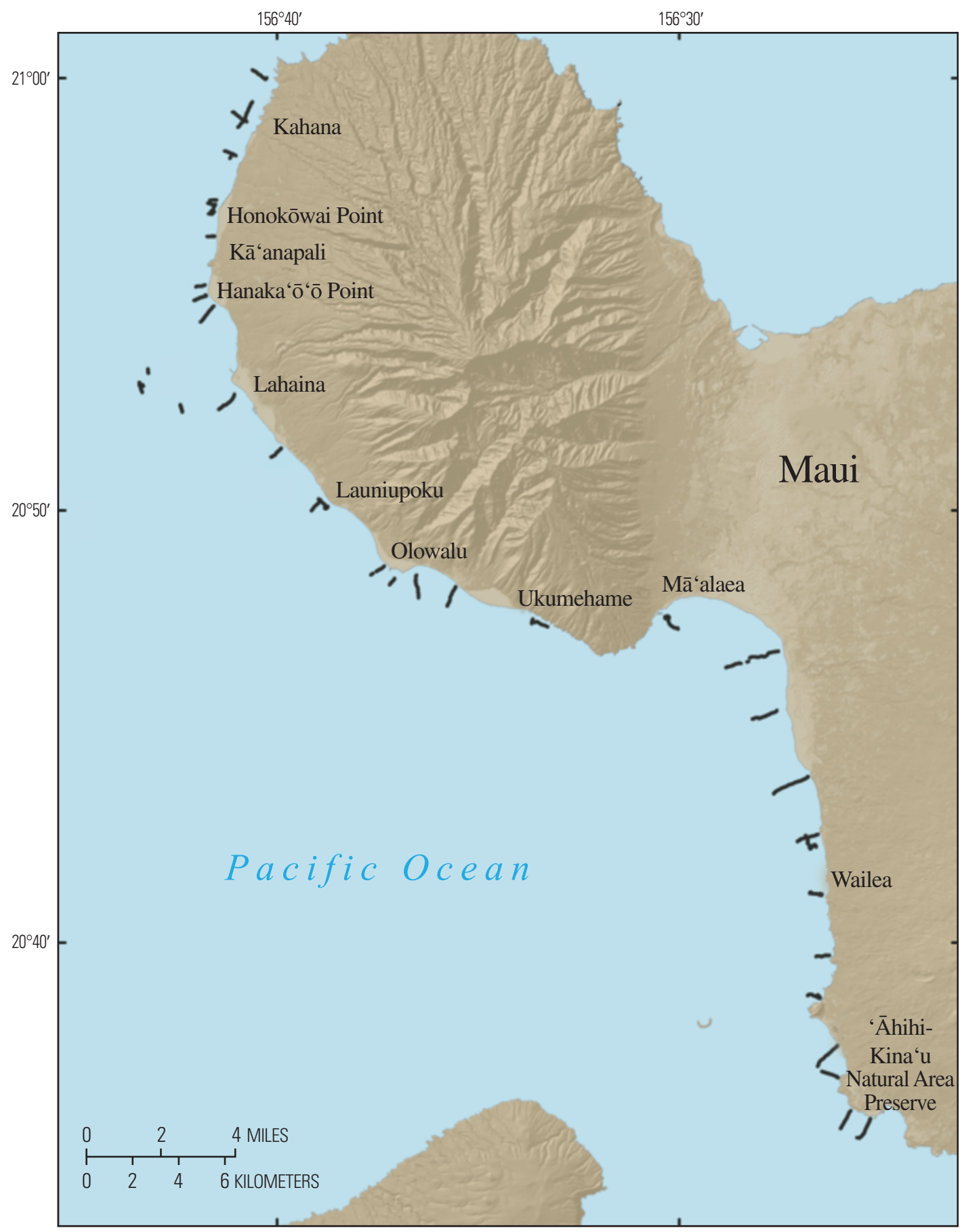

Figure 9. Northwest shore of the island of Maui, showing locations of towed-camera transects (dark-grey lines) from cruise A-2-02-HW. 


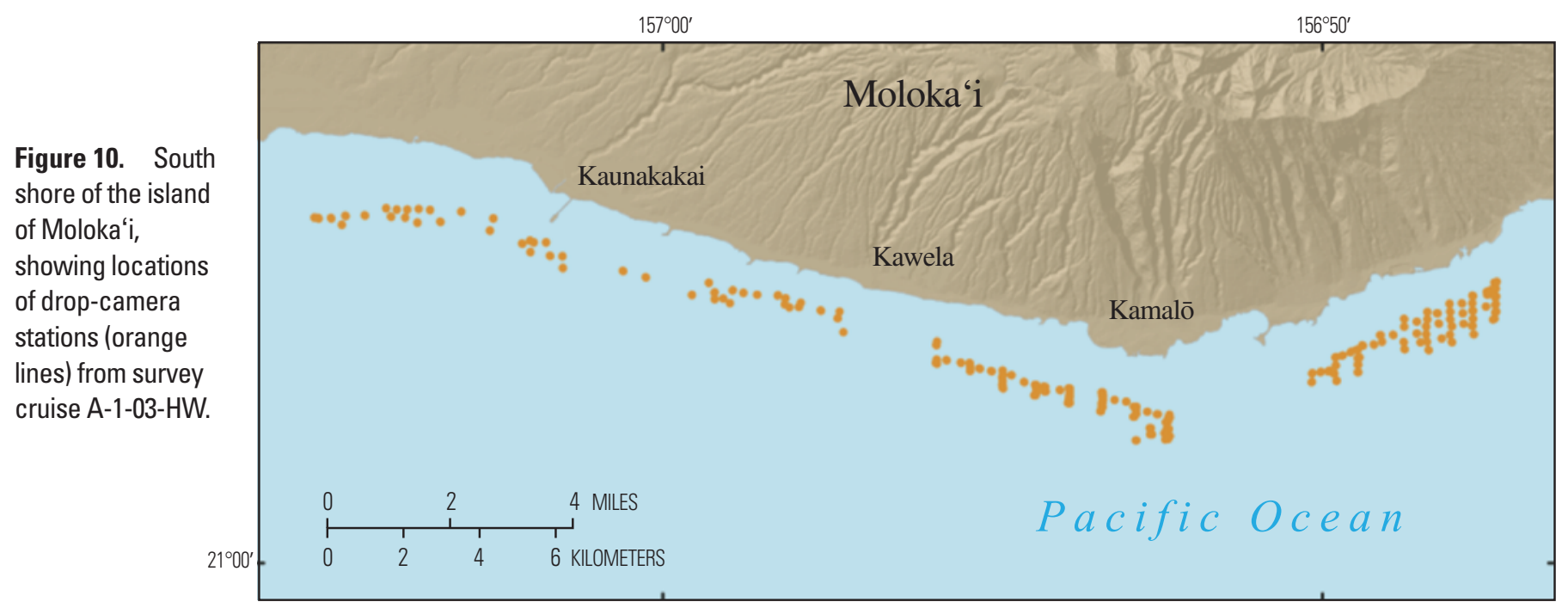

\section{Cruise A-1-03-HW: Moloka'i}

From February 10 to February 12, 2003, nearly 6 hours of underwater video footage was collected from 161 drop-camera stations along the south shore of Moloka'i using the SEAVIEWER camera system and recorded on Digital-8 videotapes (fig. 10). Position information was encoded on the audio track of the videotapes with the VMS200 system, using GPS information from a Garmin GPS76 WAAS-enabled handheld GPS unit. Water depths ranged from 4 to $32 \mathrm{~m}$. The main purpose of the surveys was to collect groundtruth and field validation data for various digital maps generated using remotely sensed images and other data.

\section{Cruise A-7-03-HW: Maui}

On July 5, 2003, nearly 2 hours of underwater video footage was collected from 32 drop-camera stations off the west coast of Maui near Honokōwai Point (drops 1, 1a, 1b, 2-19) and Hanaka ${ }^{‘}{ }^{`} \bar{o}$ Point (drops 20-30) using the SEAVIEWER camera system and recorded on Digital-8 videotapes (fig. 11) in water depths ranging from 4 to $35 \mathrm{~m}$. Position information was encoded onto the audio track of the videotapes with the VMS200 system, using GPS information from a Garmin GPS76 WAAS-enabled handheld GPS unit. The main objectives of this cruise were to characterize the overall sea-bottom type and to identify regional transitions in reef morphology, coral cover, and coral health.

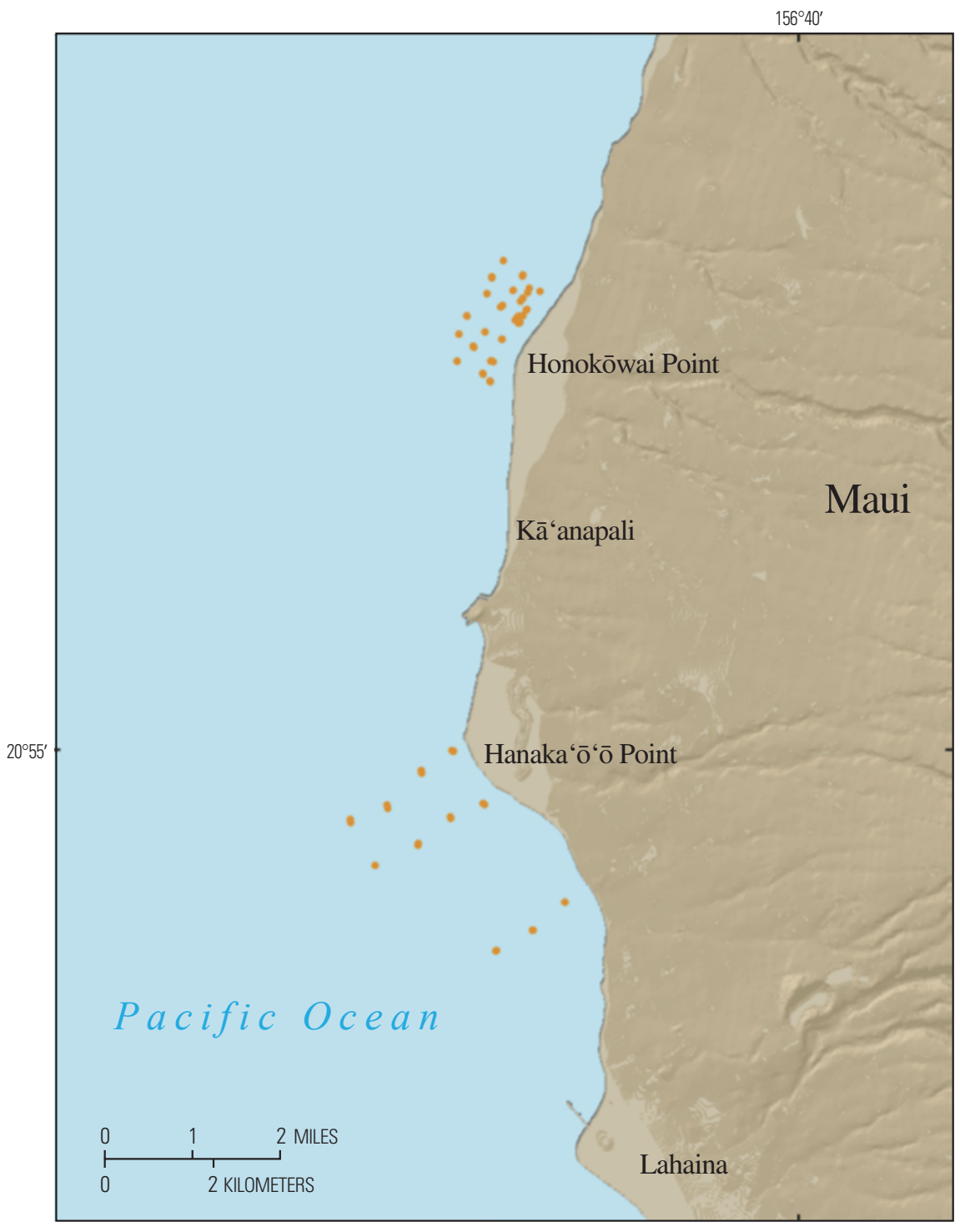

Figure 11. West coast of the island of Maui, showing locations of drop-camera stations (orange lines) from cruise A-7-03-HW. 


\section{Cruise A-2-11-MU: Maui}

From March 19 to March 21, 2011, nearly 8 hours, or more than $7 \mathrm{~km}$, of underwater video footage was collected along 17 towed-camera transects and from an additional 214 individual drop-camera stations off the west coast of Maui with the SPLASHCAM camera system and recorded on MiniDV videotapes (fig. 12) in water depths ranging from 2 to $36 \mathrm{~m}$. The cruise focused on two survey regions offshore West Maui: (1) Olowalu, between Launiupoko and Ukumehame; and (2) Kā‘anapali between Honokōwai Point and Hanaka ${ }^{`} \bar{o}^{`} \bar{o}$ Point. The camera system was manually deployed and either towed continuously behind the vessel along shore-normal transects or dropped over the side along multiple shore-normal transects at stations corresponding to the 5-, 10-, 15-, 20-, 25- and 30-m isobaths. Position information was encoded onto the audio track of the videotapes with the VMS200 system using GPS information from a Novatel Propak-G2plus GPS unit. The main objective of this cruise was to collect information about seafloor characteristics for the development of detailed benthichabitat maps.

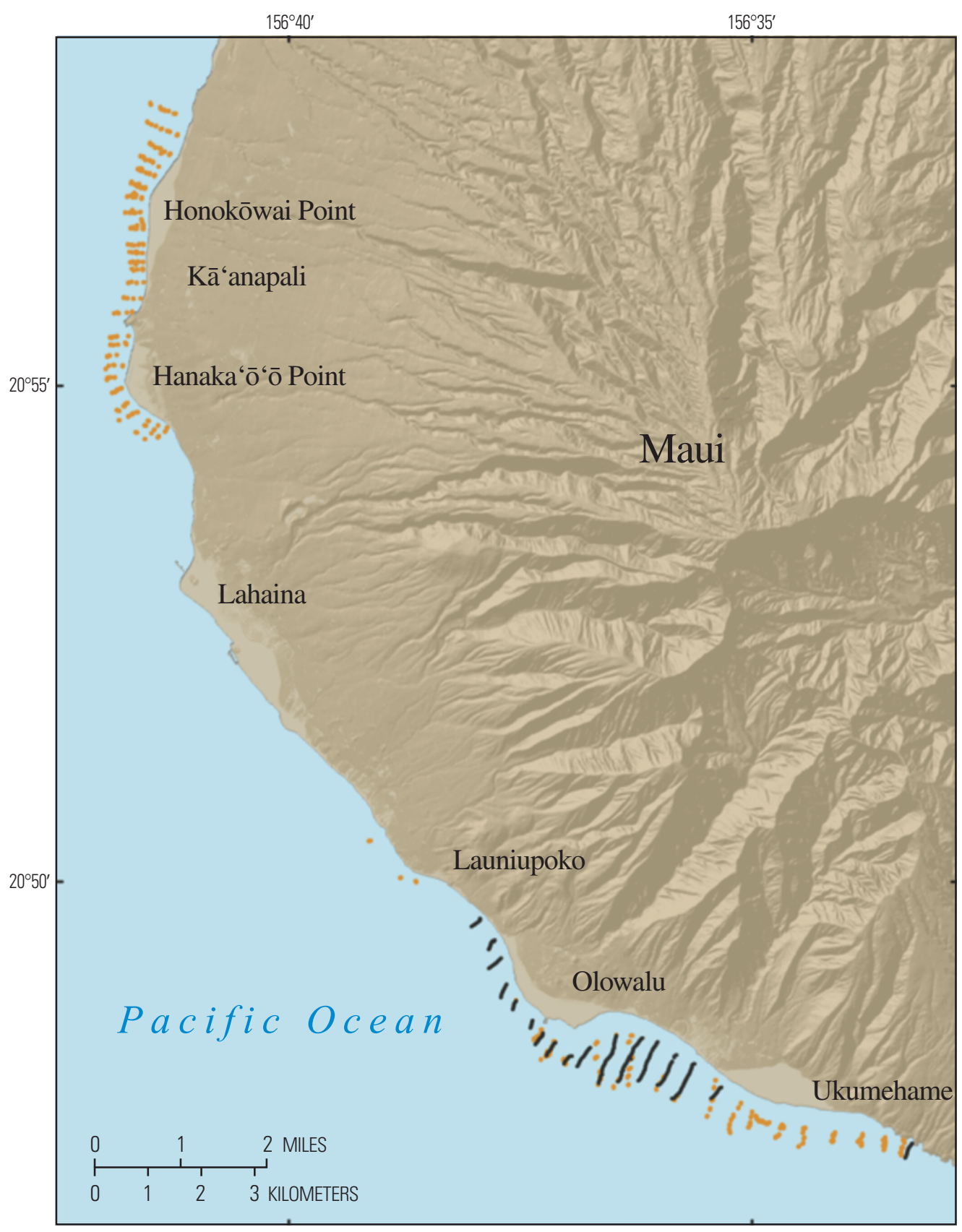

Figure 12. West coast of the island of Maui, showing locations of towed-camera transects (dark-grey lines) and drop-camera stations (orange lines) from cruise A-2-11-HW. 


\section{Data Processing}

The original analog videotapes were converted to digital files using Corel VideoStudio ProX2 (v. 12.0) software. Geo-encoding information was retained on the audio track, and automatic white-balance color corrections were applied. Individual towed-camera and drop-camera segments were clipped from the white-balanced full-length video and saved as MPEG2 files. Using MediaMapper (v. 5.3), these individual videos were reindexed, and jpg still frames were captured every $10 \mathrm{~s}$ along the video segment. Additional still images were captured for each distinct change in seafloor environment that was assumed to be continuous for $100 \mathrm{~m}^{2}$, and from each drop-camera station (a near-bottom view from the lowest point of the drop, and another from slightly higher up in the water column for a broader view). The still images were processed using Adobe Photoshop to improve quality and eliminate interlacing effects (fig. 13). After reindexing and processing, the clipped MPEG2 files were converted to .MOV format using the WinFF program. The .MOV-format video files are no longer compatible with Red Hen Systems' software, but the original MPEG2 files are archived at the USGS and available from the authors. Shapefiles were created from the MediaMapper indexes and edited in ArcGIS (v. 9.3) software to include hyperlinks to the still images and video clips of the individual segments. ArcGIS was also used to export the shapefiles as linked Google Earth kml files for users who may not have access to GIS software. The stillimage files range in size from 33 to $326 \mathrm{~KB}$; the video-clip files range in size from 2.2 to $558.8 \mathrm{MB}$.

\section{Data Catalog}

This report includes ESRI ArcMap shapefiles and Google Earth $\mathrm{kml}$ files for the locations of all video imagery, expressed as points spaced approximately every $2 \mathrm{~s}$, and for the location of still-frame images extracted from the digital video for each cruise. For cruise A-2-02-HW, separate shapefiles and $\mathrm{kml}$ files are included for three different islands: $\mathrm{O}^{`} \mathrm{ahu}$, Moloka' $i$, and Maui.

Attribute fields of the shapefiles include pointers (IMAGEPTR, VIDEOPTR) to facilitate viewing of images and video clips from within an ArcMap GIS project. Once the shapefile is added to a project and hyperlinks are enabled, the video and stills can be viewed with the user's default image viewer or video player (visit http://www.esri.com/ for more information on hyperlinks). Descriptions of the main attribute fields included in the shapefiles are listed in table 3.

Similarly, the Google Earth kml files include popup informational balloons that include html links for viewing the images and video with the user's default image viewer or video player (fig. 14). Apple Mac users should check the option to "Show web results in external browser" in Google Earth's preferences in order to bypass any plug-in conflicts.
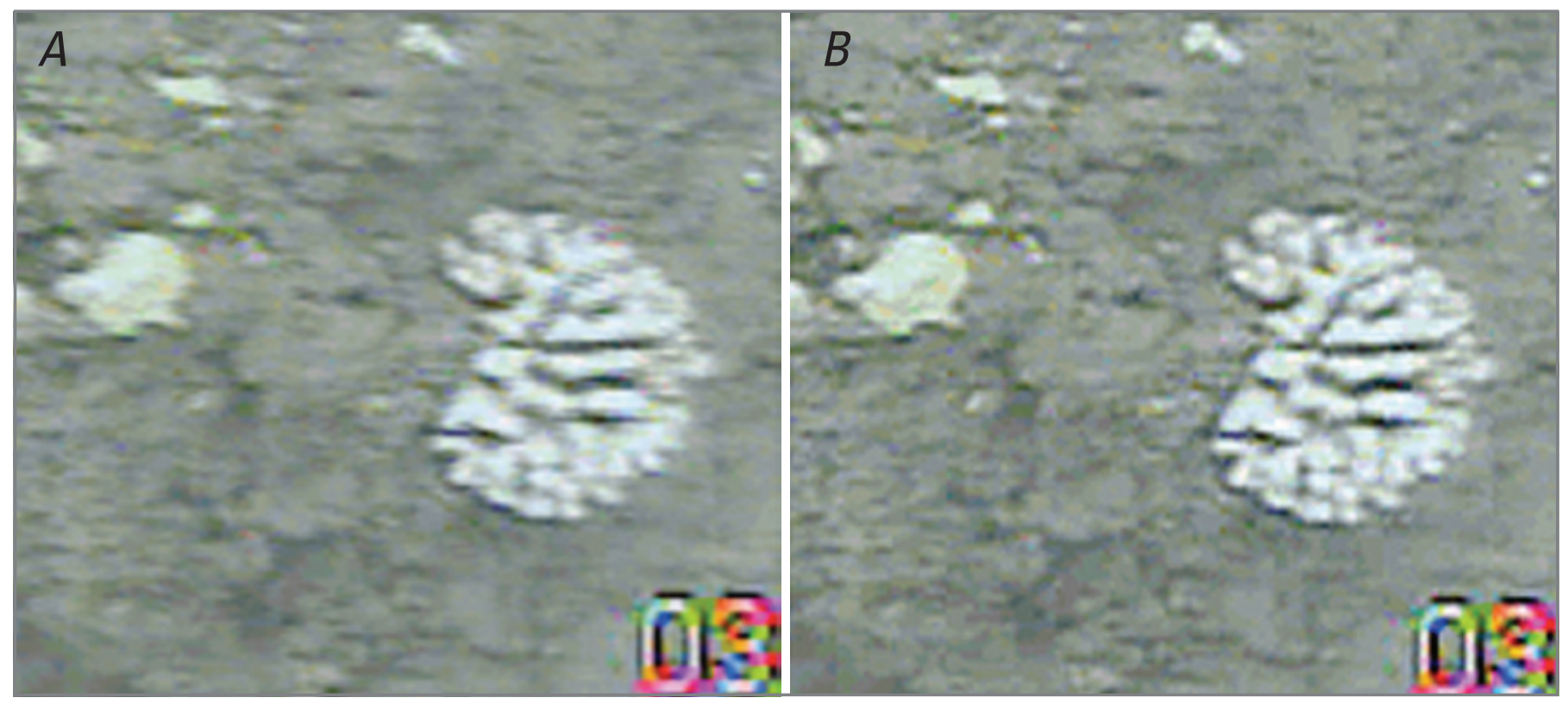

Figure 13. Typical still image as it is first captured from the video footage $(A)$ and after elimination of interlacing effects $(B)$. Field of view, approximately $50 \mathrm{~cm}$. 
Table 3. Descriptions of main attributes included in shapefiles.

\begin{tabular}{ll}
\hline \multicolumn{1}{c}{ Attribute } & \multicolumn{1}{c}{ Description } \\
\hline CRUISEID & Cruise identification \\
ISLAND & Name of nearest island \\
DATE_ & Date of collection \\
UTC & UTC time (MS OLE format) \\
LAT & Latitude \\
LON & Longitude \\
TAPESEGMT & Name of original tape source \\
IMAGENAME & Image-file name \\
VIDEOPTR & File location of video clip (for hyperlink) \\
IMAGEPTR & File location of image (for hyperlink) \\
VIDEOSZ_MB & File size (in megabytes) of video clip \\
IMAGESZ_KB & File size (in kilobytes) of still image \\
\hline
\end{tabular}

\section{Acknowledgments}

This project was funded by the U.S. Geological Survey, Coastal and Marine Geology Program, Pacific Coral Reef Project-Mike Field and Curt Storlazzi, coordinators. Josh Logan, Eric Grossman, Gerry Hatcher, Pat Chavez, Miguel Velasco, Bruce Richmond, Jodi Harney, and Hank Chezar (all USGS) provided invaluable assistance in the field data collection. Special thanks go to Eric Grossman, Kevin O'Toole, Gerry Hatcher, and Hank Chezar (all USGS) for instrument development. Betsy Gagne of the Hawai'i Department of Land and Natural Resources facilitated our access to the waters of the 'Ahihi-Kīna'u Natural Area Preserve. Captain Joe Reich of Moloka' $i$ capably and safely captained the vessel. Florence Wong and Nadine Golden (USGS) provided helpful reviews of the manuscript. Mahalo nui loa.

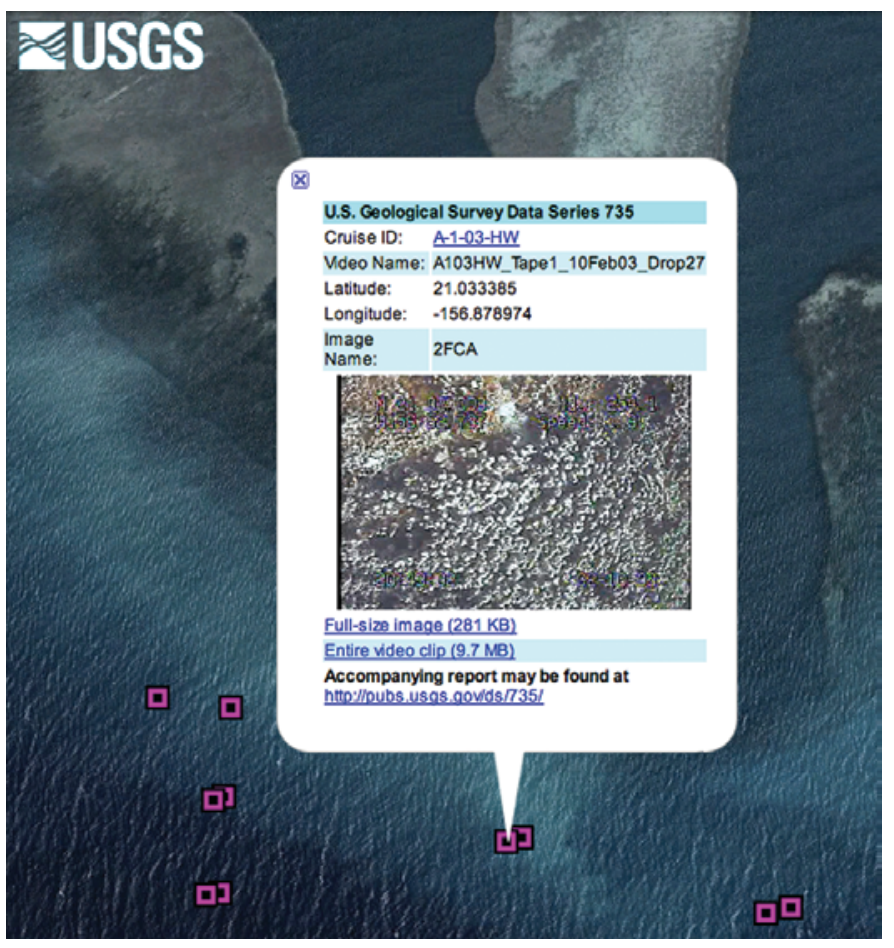

Figure 14. Screenshot showing popup informational balloon included in Google Earth kml files.

\section{Reference Cited}

Gibbs, A., Grossman, E., and Richmond, B., 2005, Summary and preliminary interpretations of USGS cruise A-2-02-HW; underwater video surveys collected off of Oahu, Molokai, and Maui, Hawaii, June-July 2002: U.S. Geological Survey Open-File Report 2005-1244, 57 p., available at http://pubs. usgs.gov/of/2005/1244/. 
This page intentionally left blank 
Menlo Park Publishing Service Center, California Manuscript approval date December 3, 2012 Edited by George Havach and Claire Landowski Design and layout by Jeanne S DiLeo 
용

흥.

을.

恚

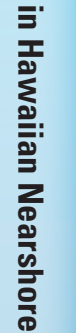

$\Sigma$

余

i

웡

黑.

ज్ 